${ }^{\odot}$ Entomologica Fennica. 23 November 2001

\title{
Meteorus corax Marshall, 1898 (Hymenoptera: Braconidae), a new species to Finland and Russian Karelia, with an overview of northern species of Meteorus parasitizing beetles
}

\author{
Petri Martikainen \& Martti Koponen
}

Martikainen, P. \& Koponen, M. 2001: Meteorus corax Marshall, 1898 (Hymenoptera: Braconidae), a new species to Finland and Russian Karelia, with an overview of northern species of Meteorus parasitizing beetles. - Entomol. Fennica 12: 169-172.

Meteorus corax (Hymenoptera, Braconidae) is reported for the first time from Finland and Russian Karelia. The Finnish specimens were reared from standing dead pine where Monochamus galloprovincialis (Coleoptera, Cerambycidae) was presumably the host, and in addition, from firewood presumably from Callidium violaceum (Coleoptera, Cerambycidae). The specimens from Russian Karelia were reared from pupae, which almost certainly originated from the larvae of Pytho depressus (Coleoptera, Pythidae). No parasitic hymenopterans have previously been recorded from the family Pythidae. The genus Meteorus includes several species yet to be found from Finland.

Petri Martikainen, Faculty of Forestry, University of Joensuu, P.O. Box 111, FIN-80101 Joensuu, Finland; E-mail: petri.martikainen@joensuu.fi Martti Koponen, Department of Applied Biology, P.O. Box 27, FIN-00014 University of Helsinki,Finland; E-mail: martti.a.koponen@helsinki.fi

Received 31 January 2001, accepted 9 April 2001

\section{Introduction}

The cosmopolitan genus Meteorus Haliday, 1835 is placed either into the tribe Meteorini in the subfamily Euphorinae (e.g. Huddleston 1980, Tobias 1986, van Achterberg 1997), or in the subfamily Meteorinae (Shaw 1985, Shaw \& Huddleston 1991, Shaw 1997). The genus includes about 200 described species, of which 50 occur in the Palaearctic region (Tobias 1986). In Finland, 23 or 24 of the Palaearctic species have been recorded. Most of the species are parasitoids of Lepidoptera, but some species parasitize Coleoptera living under bark, in wood, or in fungi.

Meteorus corax Marshall, 1898 is the largest species $(7-9 \mathrm{~mm})$ in the genus and it is as black as a raven (Corvus corax). The propodeum is divided by a sharp transverse ridge into a horizontal upper and a vertical posterior surface, and the clypeus has longitudinal folds (Tobias 1986). The nearest relative in the Palaearctic Region is $M$. sulcatus Szépligeti (see below). The distribution of $M$. corax is North and Central Europe (Austria, Germany, Sweden, Switzerland), central Russia, Siberia, Russian Far East, and the Altai mountains. Its long ovipositor suggests that host species live in wood or under bark. According to Tobias (1986) the host species are Monochamus galloprovincialis (Olivier) and M. saltuarius (Gebler) (Coleoptera, Cerambycidae). In this article we present 
new finds of Meteorus corax from Finland and Russian Karelia. These records are based on rearings.

\section{New records}

Three female specimens were reared from cocoons found in Russia, Karelia, $K b$ : Korpiselkä on 2.VII.1993 (P. Martikainen). The cocoons were found under the bark of fallen Scots pine (Pinus sylvestris). The cocoons were located very close to recently dead, almost full-grown larvae of $P$ tho depressus (Linnaeus) (Coleoptera, Pythidae), giving the impression that the parasitoids originated from the Pytho larvae (each parasitoid from a separate host larva), and that these larvae had died because of parasitization.

Another rearing was conducted in Finland, $\mathrm{Sa}$ : Juva, Otamo (68385:5509) (P. Martikainen). A recently dead pine was felled on 12.VIII.1997, and several bolts from a height of 17-21 $\mathrm{m}$ were taken into rearing. This rearing resulted in specimens of Coleoptera: Monochamus galloprovincialis, Acanthocinus griseus (Fabricius) (Cerambycidae) and Pityogenes quadridens (Hartig) (Scolytidae). In addition to the beetles, 6 females of Meteorus corax emerged. The most likely host in this case was $M$. galloprovincialis.

One female specimen was also taken from a window by author Koponen at his home. It had emerged from pine and spruce firewood. The presumed host is Callidium violaceum (Linnaeus) (Coleoptera, Cerambycidae), specimens of which were found in the same room. The origin of the wood was $S a$ : Ristiina (6826:526) and the year 1993.

\section{Other Meteorus species parasitizing beetles (Coleoptera)}

The genus Meteorus includes several species known to parasitize beetles. Some of them are already known from Finland, but many others are still waiting for their discovery in our country. To encourage coleopterologists to pay attention also to these parasitoids we compiled a list of Meteorus species that may be met when rearing certain spe- cies of beetles. This overview is based on Huddleston (1980) and Tobias (1986).

\subsection{Species reported from Finland}

Meteorus consimilis (Nees, 1834)

Has frequently been reported as a parasitoid of Scolytus multistriatus (Marsham) (Scolytidae). Reported from southern Finland (Al, Ab, N, St, Ta, Kl) by Hellén (1946). Scolytus multistriatus has not been found in Finland, thus hosts of this Meteorus species may also be some other Scolytus species, most likely $S$. ratzeburgi Janson.

\section{Meteorus longicaudis (Ratzeburg, 1848)}

Hosts: Orchesia micans (Panzer) (Melandryidae) and Eledonoprius armatus (Panzer) (Tenebrionidae). The larvae of these beetles live in bracket fungi on trees. Reported from Finland (Ab, Ta, Tb) by Hellén (1946).

\section{Meteorus obfuscatus (Nees, 1812)}

Hosts: Orchesia micans, O. minor Walker, Triplax russica (Linnaeus) (Erotylidae). Reported from Finland (Al, Ab, N) by Hellén (1946).

Meteorus vexator (Haliday, 1835)

Hosts: Biphyllus lunatus (Fabricius) (Biphyllidae) and Mycetophagus sp. (Mycetophagidae). Reported from Finland (Al, Ab, N, Sa, Kl, Obo) by Hellén (1946) and by Nuorteva and Järvinen (1961).

\subsection{Meteorus species yet to be found from Fin- land}

Meteorus sulcatus Szépligeti, 1896

Body smaller (4 mm) than in M. corax. Propodeum fairy flat, lacking sharply transverse ridge. Clypeus 
is punctate and lustrous. Hosts: Semanotus undatus (Linnaeus), Molorchus umbellatarum (Schreber), Phymatodes alni (Linnaeus) and Pogonocherus sp. (Cerambycidae). Distribution: Europe (Austria, Great Britain, Netherlands, former Yugoslavia) and Russia (Krasnodar Territory, Pacific Coastal Region).

Meteorus tabidus (Wesmael, 1835)

Hosts: Saperda populnea (Linnaeus), S. scalaris (Linnaeus) and Leiopus nebulosus (Linnaeus) (Cerambycidae). Also doubtful old host records from several species of Lepidoptera. Distribution: Europe (including Sweden) and Russia.

Meteorus breviantennatus Tobias, 1986

Hosts: Tomicus minor (Hartig) and Ips acuminatus (Gyllenhal) (Scolytidae). Known from Russia (Ulyanovsk Region) and Georgia.

Meteorus varinervis Tobias, 1986

Hosts: Pityogenes chalcographus (Linnaeus) and Pityophthorus micrographus (Linnaeus) (Scolytidae). Russia (Arkhangelsk).

Meteorus ipidivorus Tobias, 1986

Host: Ips acuminatus (Gyllenhal). Russia (Middle Volga Region, Western Siberia).

Meteorus profligator (Haliday, 1835)

Host: Cis boleti (Scopoli) (Cisidae). Austria, Great Britain, Ireland, Netherlands.

Meteorus punctifrons Thomson, 1895

Host: Corticeus longulus (Gyllenhal) (Tenebrionidae). Reared from cut wood infested by bark beetles. Sweden (north to Västerbotten), France.

\section{Discussion}

Most species of Meteorus are koinobiont endoparasitoids of lepidopteran larvae, but some species exclusively attack larval Coleoptera (Shaw \& Huddleston 1991). Before the host is fully grown the parasitoid larva emerges, and immediately or after moving away for a short distance, spins a cocoon, usually at the end of silken thread about 1-8 (exceptionally up to 20) cm long (Shaw \& Huddleston 1991). However, those Meteorus species that attack coleopterous larvae form stalkless cocoons within the beetle gallery and are regarded as relatively primitive (Shaw 1997). The find of $M$. corax from a dead pine attacked by Monochamus galloprovincialis is consistent with earlier observations that $M$. corax parasitize larvae of Monochamus (Tobias 1986), whereas the current record possibly from Pytho depressus is more notable. A brief literature survey did not yield any records of ichneumonids (Yu 1999), braconids (Shenefelt 1980) or chalcidoids (Noyes 1998) parasitizing species belonging to the family Pythidae, although it is likely that such species exist. Unfortunately the present host record is not absolutely certain because larvae of M. corax were not actually seen emerging from their assumed hosts, Pytho-larvae. It is thus possible, albeit not very likely, that the host may have been some other species inhabiting the same dead tree, such as Rhagium inquisitor (L.), Acanthocinus aedilis (L.) or Monochamus galloprovincialis which are typical species in recently dead pines. However, more detailed collection notes of other species were not made because Pytho depressus clearly seemed to be the host. If $M$. corax commonly parasitizes $P$ tho species, it should be rather easy to verify this observation by making new rearing experiments with this abundant saproxylic beetle.

As the list above indicates, there are several Meteorus species yet to be discovered in Finland. In most cases the known host species are common beetles living in forests. Furthermore, many other beetle species can evidently be suitable hosts for these, and for other interesting parasitoids. It is thus possible to make significant finds even by rearing abundant beetle species from trivial forest habitats. 


\section{References}

Achterberg, C. van 1997: Braconidae. An illustrated key to all subfamilies. - ETI World Biodiversity Database CD-ROM Series.

Hellén, W. 1946: Für die Fauna Finnlands neue Braconiden (Hym.) II. — Notulae Entomol. 25: 130-137.

Huddleston, T. 1980: A revision of the western Palaearctic species of the genus Meteorus (Hymenoptera: Braconidae). — Bull. Br. Mus. (Nat. Hist.) Entomol. ser. 41(1): $1-58$.

Noyes, J. S. 1998: Catalogue of the Chalcidoidea of the World. - ETI Biodiversity Catalogue Database and Image Library CD-ROM Series.

Nuorteva, P. \& Järvinen, U. 1961: The insect fauna of the nests of the sand martin (Riparia riparia L.) in Finland. - Ann. Entomol. Fennici 27: 197-204.

Shaw, M. R. \& Huddleston, T. 1991: Classification and biology of braconid wasps (Hymenoptera: Braconidae).
- Handbooks for the Identification of British Insects 7(11): 1-126.

Shaw, S. R. 1985: A phylogenetic study of the subfamilies Meteorinae and Euphorinae (Hymenoptera: Braconidae). - Entomography 3: 277-370.

Shaw, S. R. 1997: Subfamily Meteorinae. — In: Wharton, R. A., Marsh, P. M. \& Sharkey, M. J. (eds.), Manual of the New World genera of the family Braconidae (Hymenoptera). Special publication of the International Society of Hymenopterists 1. pp. 326-330.

Shenefelt, R. D. 1980: Braconidae 11. — In: Achterberg, C. van \& Shenefelt, R. D. (eds.), Hymenopterorum Catalogus (nova editio) 16: 1-384.

Tobias, V. I. 1986: [8.] Subfamily Euphorinae. — In: Tobias, V. I. (ed.), Keys to the insects of the European part of the USSR. Vol. 3, Hymenoptera, part 4: Nauka Publisher, Leningrad. pp. 181-250. [In Russian].

Yu, D. S. 1999: Interactive catalogue of World Ichneumonidae 1998. - CD-ROM, Taxapad, Bentall Centre, Vancouver, Canada. 